Ivo Blom*

\title{
Terugblikken: Nederlandse non-fictiefilms van rond de eeuwwisseling (I)
}

'Er schijnen toch nog meer oude films te bestaan dan wij vermoedden.' ${ }^{\text {I }}$

Op 29 augustus 1902 werd het Amsterdamse Flora-theater van Franz Anton Nöggerath praktisch geheel door brand verwoest. Een dienstbode liet in de keuken achter het theater een pot kokend vet vallen, waardoor binnen de kortste keren het hele pand in lichterlaaie stond. Het theater, de filmstudio op het dak en het atelier waar de films werden ontwikkeld, brandden af, maar werden nadien weer geheel opgebouwd. Onherstelbaar echter was het verlies van Nöggeraths films, waaronder diverse unieke kopieën. ${ }^{2}$ Lange tijd werd gedacht dat daarmee alle films van Nöggerath van vóór I902 verloren waren gegaan. Nu blijkt echter dat zowel het Filmmuseum als Beeld en Geluid vroege actualiteitenfilms bezitten waarvan zeker een deel aan Nöggerath kan worden toegeschreven.

Zowel het Filmmuseum als Beeld en Geluid bezitten namelijk zeldzaam nitraatmateriaal van een serie actualiteitenfilms die in de jaren I899-I902 in Nederland zijn opgenomen. Naast de Biograph-films die begin jaren negentig door het Filmmuseum werden teruggevonden, met veel moeite werden geconserveerd door het bedrijf Image Creations en opnieuw in binnen- en buitenland werden vertoond, begeleid door wetenschappelijke publicaties, is dit het oudste Nederlandse filmmateriaal. Tot nu toe zijn deze opnames echter nauwelijks onderzocht. Net als de gefilmde actualiteiten van de gebroeders Lumière, betreft dit materiaal - overwegend single take - straatbeelden, beelden van publieke gebeurtenissen waarbij met name het koninklijk huis en staatslieden (de eerste filmsterren) betrokken waren, en impliciet zijn het vaak beelden van toeschouwers, van mensen in stedelijke omgevingen - in zekere zin de stand-ins van andere toeschouwers die deze films zagen. Tot voor kort werden de films toegeschreven aan Willy Mullens, maar we

Ivo Blom is universitair docent Algemene Cultuurwetenschappen aan de Vrije Universiteit, Amsterdam en leidt daar de masterspecialisatie Comparative Arts and Media Studies: Intermedialities. Blom studeerde kunstgeschiedenis in Utrecht en Leiden, was werkzaam in het filmarchief van het Filmmuseum en promoveerde in 2000 aan de UvA. Zijn handelseditie Jean Desmet and the Early Film Trade (2003) werd een veelbesproken boek. Ivo Blom publiceert regelmatig in binnen- en buitenland en is gespecialiseerd in vroege film, Italiaanse film, film en visuele cultuur, en bioscoopcultuur. In 2004 was hij coredacteur van het TMG-themanummer 'Games' en in 2006 van het themanummer 'Cinema Context'. Tussen 2006 en 2008 was hij gastdocent aan de Universiteit van Siena en in 2007 en 2010 bij het Koninklijk Nederlands Instituut te Rome. In 2009 organiseerde hij de ESF exploratory workshop 'Intermedialities: Theory, History, Practice'. www.ivoblom.nl (blog annex homepage) 
kunnen een groot deel, zo niet alle films toeschrijven aan Anton Nöggerath senior, rond I900 de belangrijkste concurrent van Biograph wat betreft de productie van actualiteitenfilms in Nederland.

Dit filmmateriaal werd in I928 door ir. A. Slingervoet Ramondt geschonken aan het Nederlandsch Centraal Filmarchief (NCF), een privé-initiatief in de jaren twintig om Nederland geografisch en historisch te documenteren via filmbeelden en deze beelden voor het nageslacht te bewaren. Tevens verzamelde en archiveerde het NCF al geschoten filmmateriaal dat Nederland documenteerde en zo ontstond het gebruik van film als historische bron. ${ }^{3}$ Daarmee liep het NCF vooruit op de huidige instellingen als Beeld en Geluid en het Filmmuseum. Bij het NCF werd het genoemde vroege filmmateriaal via de compilatie Cinematografische terugblik naar het eind van de vroege en het begin dezer eeuw in een nieuwe constellatie gegoten en zo van een nieuwe betekenis voorzien als promotiemateriaal voor het NCF. Toen het materiaal na de Tweede Wereldoorlog bij het Filmmuseum en Beeld en Geluid arriveerde, werd het daar met de toen beschikbare kennis en technologie geconserveerd en in andere compilaties herschikt, zodat het een bescheiden derde leven kreeg. ${ }^{4}$ De actualiteitenfilms van Nöggerath verdienen vandaag de dag niet alleen een nadere analyse en contextualisering via dit artikel, maar ook een vierde dimensie via een adequate, moderne herconservering - evenals nieuwe vertoningmogelijkheden.

\section{Film als historische bron. Inhoud en vorm}

In zijn baanbrekende studie Eyewitnessing. The Use of Images as Historical Evidence heeft Peter Burke aangetoond hoe belangrijk het is om visuele bronnen te gebruiken wanneer we geschiedenis schrijven, maar ook hoe belangrijk het is om een kritisch oog erop na te houden met betrekking tot visuele bronnen, gebaseerd op erkenning van bijvoorbeeld het doel van de beelden. We kunnen in het voorliggende onderzoek een intermediale laag toevoegen, door deze beelden te plaatsen binnen bepaalde iconografische tradities vanuit de fotografie en ansichtkaartenproductie. In zijn inleiding in Eyewitnessing geeft Burke aan hoe de smalende houding tegenover het beeld door historici decennialang een obstakel is geweest om beelden als historische bronnen te hanteren. Burke geeft aan dat zowel teksten als beelden niet onproblematisch zijn en geen vaste waarheden bevatten. Daarom zou de term trace (spoor) toepasselijker zijn dan de term source (bron). Behalve als bron kunnen beelden het verleden levendiger voorstellen, zoals Francis Haskell en Stephen Bann hebben opgemerkt; ze kunnen ons face to face brengen met de geschiedenis. Beelden lijken te fungeren als sterke ooggetuigen. ${ }^{6}$

Burke waarschuwt terecht dat allerlei soorten van visuele bronnen meegenomen moeten worden, maar ook dat we ons bewust moeten zijn van veranderingen in de soorten van beelden die in bepaalde tijden en plaatsen beschikbaar zijn. Hij noemt daarbij twee omslagen in het bijzonder: de opkomst van het gedrukte beeld en de opkomst van het fotografische beeld (waaronder hij ook film en televisie schaart). 


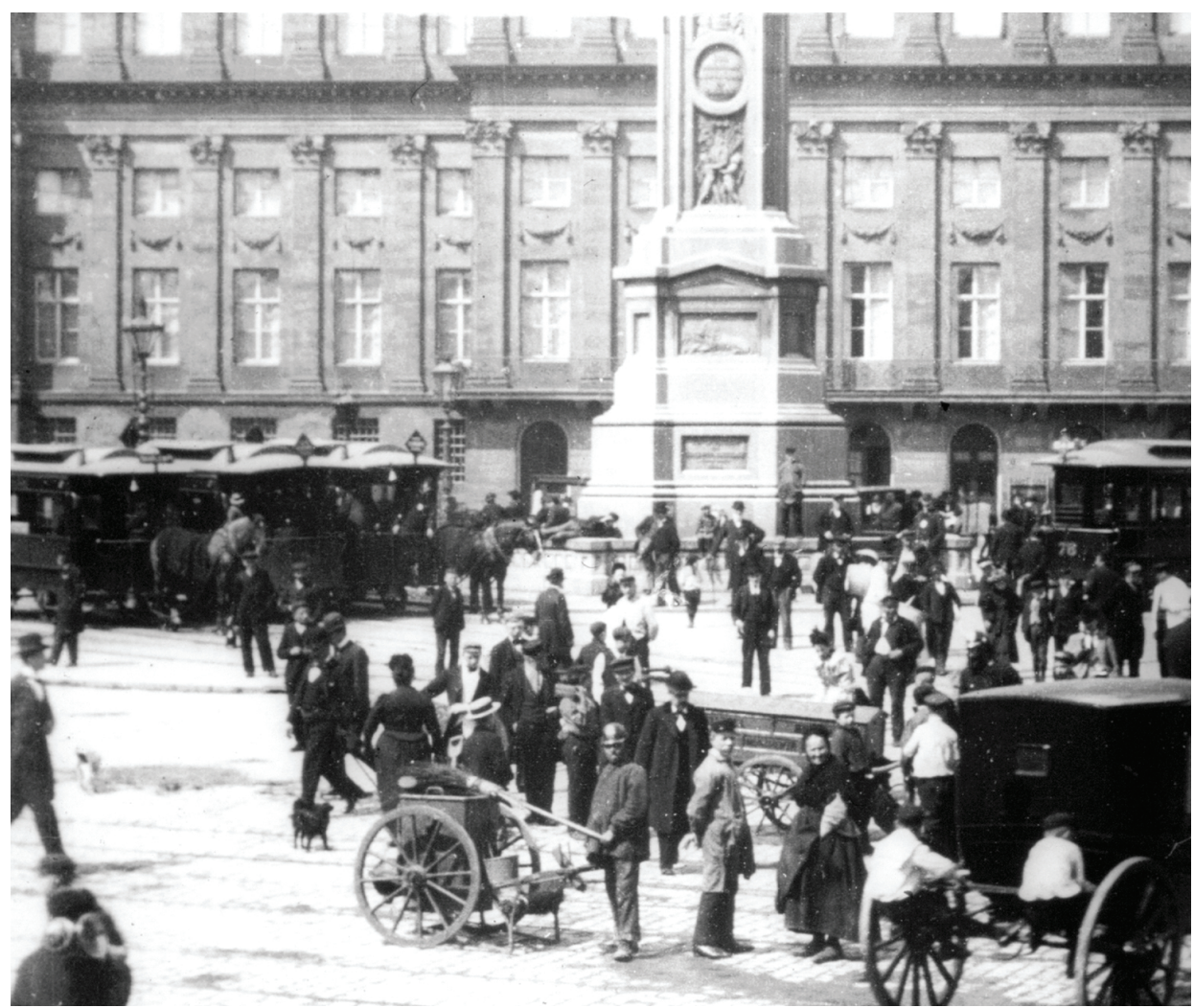

De Dam in 1900. Bron: collectie EYE Filminstituut Nederland

Niet alleen zien we een snellere productie en distributie, maar ook een snellere uitbreng van beelden nadat de gebeurtenissen die ze verbeelden hebben plaatsgevonden, plus een enorme groei in het aantal beelden dat voor gewone mensen beschikbaar is. De verveelvoudiging van beelden heeft echter niet geresulteerd in een verlies van aura, zoals Walter Benjamin beweerde,7 maar eerder in een iconisering van bepaalde beelden of van bepaalde vastgelegde gebeurtenissen of plaatsen, zoals monumenten of toeristische locaties. Terwijl Carr in What is History stelde: 'Study the historian before you begin to study the facts', zouden we ook het gebruik en het doel van beelden eerst moeten onderzoeken, voordat we ze gebruiken als bron. ${ }^{8}$ Beelden hebben in dat opzicht zo hun eigen point of views. Anderzijds heeft men binnen de geschiedschrijving de neiging uitsluitend naar de inhoud van het beeld te kijken en niet naar de vorm. Daardoor worden mediumspecifieke en mediumoverstijgende formele kwaliteiten als compositie, kadrering, dieptewerking, camerabeweging of montage niet meegenomen in de verklaring, terwijl die kwaliteiten er juist ook toe doen. Films zijn geen teksten die toevallig met beelden worden verteld. Binnen de kunsthistorische academische traditie - waarbinnen ik zelf ook gevormd ben - wordt juist altijd eerst gekeken naar de formele aspecten van het object alvo- 
rens tot de inhoud en interpretatie over te gaan. Laten we dus eerst eens kijken naar de films zelf en dan de beelden interpreteren, op basis van hun functies, door de tijden heen: ten tijde van hun productie rond I9०0 en later bij het NCF.

Het bij het Filmmuseum en bij Beeld en Geluid opgeslagen materiaal bestaat uit een aantal nitraatnegatieven waarvan niet duidelijk is of dit de oorspronkelijke films betreft of de duplicaten die in de jaren twintig door het NCF zijn gemaakt van de oorspronkelijke films. Het betreft de volgende films: I. HET TE WATER LATEN VAN DE KRUISER KONINGIN REGENTES OP DE MARINEWERF (25 april 1900), 2. PAUL KRUGER OP HET VREDENOORDPLEIN (26 juni 1901), 3. DE MAASBRUG OMSTREEKS I9OI, 4. OPENING STATEN GENERAAL (17 september 1901), 5. INTOCHT BOERENGENERAALS (september 1902), 6a. AANKOMST PAUL KRUGER OP I2 DECEMBER I9O0, 6b. AANKOMST PAUL KRU. GER OP I2 DECEMBER I9O2, 7. DE DAM OMSTREEKS I9OI, 8. INTOCHT VAN HERTOG HENDRIK VAN MECKLENBURG EN H.M. DE KONINGIN AAN HET STAATSSPOOR, 9. HUWELIJK VAN HET KONINKLIJK ECHTPAAR OP 7 FEBRUARI I9OI, OPNAMEN VAN DE RIJTOER, IO. MASKERADEFEESTEN, HISTORISCHE OPTOCHT. 9 De genoemde titels zijn door het NCF gegeven.

\section{Casestudy: beelden van de Dam}

Ik wil hier allereerst stilstaan bij twee single take opnames van de Dam te Amsterdam, allebei van tussen I900 en I902. Aangezien de gebroeders Lumière jammer genoeg niet de moeite hebben genomen opnames in Nederland te maken, ${ }^{\text {ז }}$ zijn deze twee opnames samen met een opname door het Nederlandse filiaal van American Mutoscope \& Biograph Company (AMBC) de oudste stadsbeelden op film van de Dam. Stadsbeelden, omdat de echt oudst bewaarde filmbeelden waarop de Dam zichtbaar is die zijn van de kroning van Wilhelmina (1898), gefilmd door Biograph voor hun Britse filiaal, de British Mutoscope and Biograph Syndicate, en aangeduid als CORONATION OF QUEEN WILHELMINA OF HOLLAND AT AMSTERDAM. Biograph begon daarmee zijn filmproductieactiviteiten in Nederland. ${ }^{\text {II }}$ Biograph-cameraman en -filmproducent William (W.K.L.) Dickson kwam naar Amsterdam om de inhuldiging op 8 september I898 vast te leggen, die nationaal maar ook internationaal werd gezien als een grote gebeurtenis. Dickson filmde onder andere op de Dam het binnengaan en uitkomen van de nieuwe koningin uit de Nieuwe Kerk, waar zij werd ingehuldigd. Dickson schoot voor het Britse filiaal ook nog wat lokale opnames dat jaar, onder meer in Scheveningen. ${ }^{\mathrm{I} 2}$ In december 1898 werd een Nederlands filiaal opgericht, de Nederlandsche Biograaf en Mutoscope Maatschappij, dat niet alleen beelden van Amsterdam maakte zoals een vaart door de Prinsengracht, waarbij de zware Biograph-camera een soort natuurlijke tracking shots maakte terwijl de boot vooruit voer. Ook produceerde Biograph in I899 een serie single take opnames voor de Nederlandse revue DE NIEUWE PRIKKEL van August Reijding. ${ }^{\mathrm{I3}}$ Die filmische inserts waren enerzijds geënsceneerde scènes maar anderzijds ook simpelweg stadsbeelden die binnen de context van de revue een bijzondere betekenis kre- 


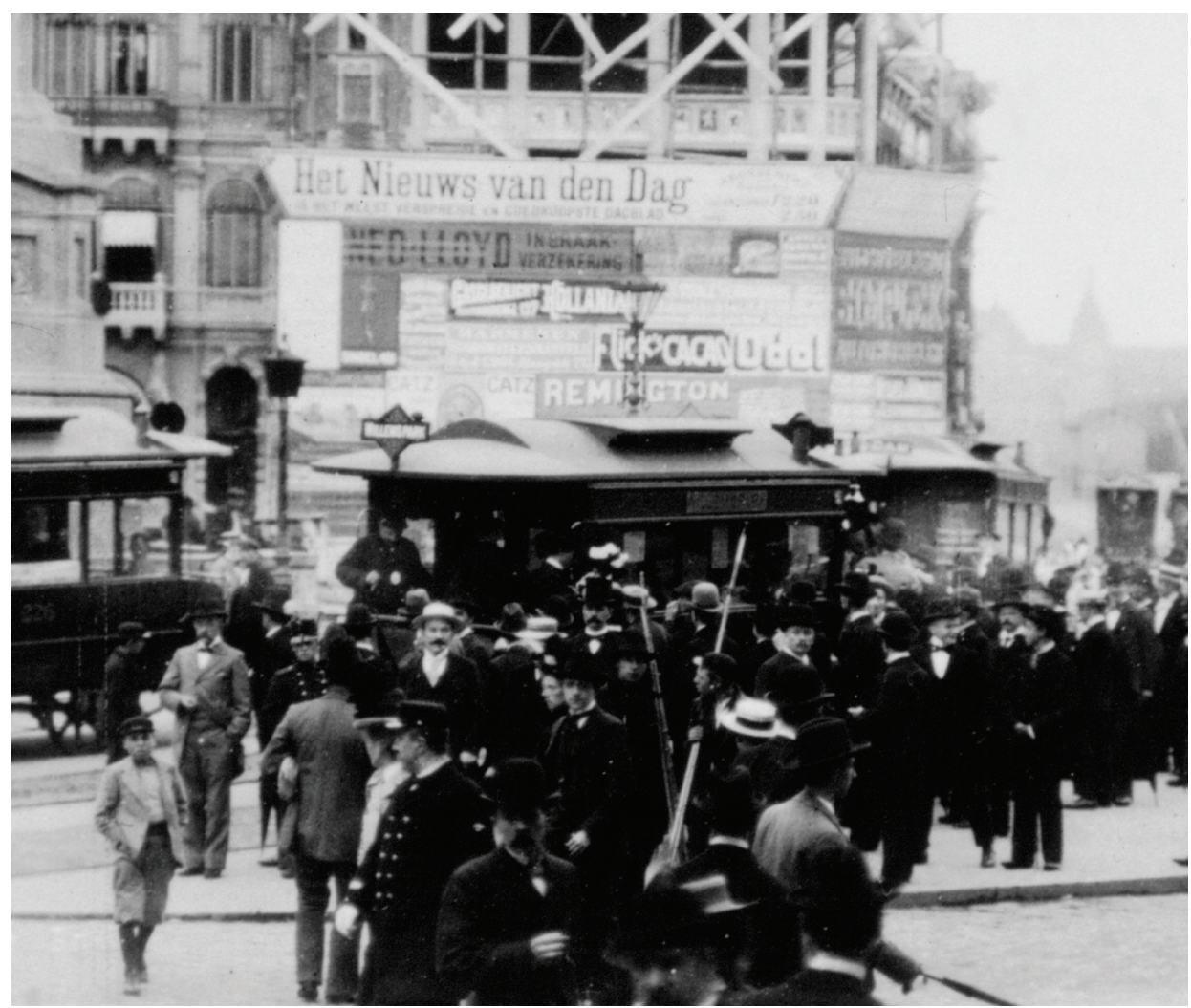

'Een trambestorming op zondag op den Dam'. Nederlandsche Biograaf a Mutuscope Maatschappij 1899. Bron: collectie EYE Filminstituut Nederland

gen, zoals een opname van mensen die een paardentram op de Dam in- en uitlopen, getiteld EEN TRAMBESTORMING OP ZONDAG OP DEN DAM (I899).

Dit is de oudste filmopname van de Dam waarbij de locatie niet toevallig decor is van een gebeurtenis maar doel op zich. De opname is echter van zo dichtbij genomen dat hij bijna overal zou kunnen zijn gemaakt. Dat is nogal een paradox voor een van de eerste actualiteitenfilms van Amsterdam die, binnen het kader van de revue, juist bedoeld was om toeristische promotie voor de stad te maken. De opname focust echter alleen op de massa als onderwerp, terwijl de tram en een grote schutting op de achtergrond, bedekt met affiches, als entourage dient. De film documenteert dan ook een specifiek moment. Achter de schutting werd namelijk op dat moment het nieuwe café Bisschop opgetrokken. Het werd juist in I899 in eclectische stijl en in vergrote versie gebouwd, op de hoek van Dam en Damrak, en verving een eeuwenoud café met dezelfde naam. Op I6 december I899 werd het geopend. ${ }^{\mathrm{I}}$ 
Aangezien een van de twee opnames van de Dam van het NCF het nieuwe café Bisschop voltooid laat zien, zijn beide opnames later gemaakt, vermoedelijk tussen I900 en I902. In contrast met de Biograph-opname en zoals Eva Hielscher heeft aangegeven in haar masterscriptie, ${ }^{15}$ zien we in de films van Nöggerath geen anonieme ruimte, geen non-place in de terminologie van Marc Augé, maar we herkennen monumentale, herkenbare en welbekende gebouwen. ${ }^{16}$ In de eerste opname zien we op de achtergrond het Koninklijk Paleis op de Dam, het voormalige Stadhuis, gebouwd tussen i648 en I665 naar een ontwerp van Jacob van Campen. Op de voorgrond herkennen we een deel van het grote monument dat toen in de volksmond bekend was als Naatje op de Dam of Naatje van den Dam. Het beeld bovenop was ontworpen door Louis Royer, terwijl Tetar van Elven het voetstuk ontwierp. Naatje werd in 1856 onthuld door koning Willem III. Officieel heette het de Eendracht en tot I9I4 was dit het nationale monument dat de Tiendaagse Veldtocht tegen de Belgen van I83I herdacht. ${ }^{17}$ Een paradoxaal monument, omdat niet alleen België uiteindelijk onafhankelijk werd en dus won van de Nederlanders, maar ook omdat Royer van oorsprong een Belg was en de zachte steen die verantwoordelijk was voor het verval van het beeld uit België afkomstig was. Vanwege zijn inferieure toestand - het beeld werd aangevreten door regen en vorst en er vielen stukken van af - werd Naatje een populair woord om een waardeloos object aan te duiden: 'ik vind het maar Naatje'. Het monument, of wat ervan over was, werd in I9I4 ontmanteld. Helaas heeft de opname geleden onder nitraatplak, maar de opname bevat ook hinderlijke lichtflitsen die mogelijk met slechte ontwikkeling destijds te maken heeft.

In de andere opname van de Dam van het NCF is het shot van bovenaf genomen en laat het nog meer panoramische ruimte en nog meer herkenbare monumenten zien. Om te beginnen is dat de oude Beurs van architect Jan David Zocher, gebouwd tussen I84I en I845 en gesloopt vanaf juli I903 nadat de nieuwe Beurs van Berlage, begonnen in 1898 , in mei 1903 werd voltooid. ${ }^{18}$ In de jaren tien zou op de plek van de Beurs warenhuis De Bijenkorf worden gebouwd. De oude Beurs met zijn strenge neoklassieke gevel, zijn enorme Ionische zuilen en zijn kale zijvleugels, veroorzaakte protesten en bijnamen als 'mausoleum', maar het gebrek aan ramen had praktische motieven, aangezien het graan dat hier werd aangeboden bij voorkeur met indirect licht werd beoordeeld. Van de drie hier besproken films, is deze opname de meest expliciete in het tonen van herkenbare gebouwen en plekken; het laat de Beurs in heel zijn afmetingen zien. Links ervan zien we ook het café Bisschop en andere gebouwen rond de Dam, richting de Nieuwe Kerk. Helemaal links in beeld zien we de rechterhelft van het nationaal monument.

Toch kan behalve de architectuur de menselijke - en dierlijke - actie in beeld in beide films ons niet ontgaan. Vooral als je de films herhaaldelijk ziet, valt je op hoe deze films de Dam tonen als een belangrijk verkeersknooppunt waar paardentrams hun eindhaltes hebben. In de opname met de Beurs in beeld zien we duidelijk hoe een paard wordt uitgespannen aan één kant van de tram en wordt aangespannen aan de andere kant, omdat veel trams hun terminus op de Dam hadden, vanwaar 
aparte trams naar het Centraal Station op en neer reden. Blijkbaar was het gemakkelijker om het paard te verwisselen dan om extra rails aan te leggen en zo de tram een rondje te laten rijden voordat deze terugreed. Deze twee opnames zijn samen met de opname van Biograph de oudste Nederlandse filmbeelden van paardentrams in actie en vermoedelijk ook de enige die het systeem van uit- en aanspannen laten zien. Rond I904 waren de meeste paardentrams in Amsterdam door elektrische trams vervangen. ${ }^{19}$ Afgezien van de actualiteitenfilms van de NCF-collectie en van Biograph zijn er geen non-fictiebeelden van Amsterdam overgebleven die verder teruggaan dan ca. I904. Deze filmbeelden zijn dus niet alleen zeldzaam, ze documenteren ook verloren gegane praktijken en verdwenen infrastructuren. Naast de paardentrams zien we ook (huur)rijtuigen, platte wagens met goederen, handkarren, fietsen en een paard met kar die melkkratten lijkt te vervoeren.

Opvallend ook zijn de verschillende kostuums en uniformen die de mensen dragen en die hun beroepen en sociale klassen aanduiden. In de film met het Koninklijk Paleis in beeld zien we eerst twee straatjongens die stiekem meeliften met een koets die van linksonder naar midden rechts het beeld uitrijdt. Halverwege zien we een chique meneer met hoge zijde en overjas van linksonder naar rechtsmidden oversteken; vermoedelijk komt hij net van de Beurs. Anderzijds zien we ook vertegenwoordigers van de middenklasse met schorten voor en arbeiders met petten op die naar linksonder, richting de Warmoesstraat lopen - offscreen, links achter de camera. We zien ook dienstmeisjes, keurig gekleed met gesteven schorten en bijbehorende mutsjes; oude vrouwen met schorten; maar ook modieuze personen, zoals een dame gekleed in een lichte jurk, korte mantel, en typische korte verticale hoed (de mode rond I900), plus een paar mannen met bolhoeden. Opmerkelijk zijn de toeschouwers die de camera observeren: een gemeentelijke straatveger met een hondenkar, een broodbezorger in witte outfit en met bakkersfiets, een oude vrouw met een schort, een jongen die eerst rondjes fietst door het beeld en zich dan bij de rest van de kijkers voegt. Natuurlijk zien we ook de verschillende paardentrams, karren en koetsen die passeren, op de voor- of achtergrond. De film met de Beurs geeft ook veel ruimte aan de voetgangers in beeld, hoewel de paardentrams prominenter de ruimte vullen. We zien hier geen toeschouwers die naar de camera kijken - als ze dat al doen dan is de afstand te groot en het beeld niet scherp genoeg - maar wel is duidelijk dat sommige mensen blijven stilstaan, zoals een dame met een parasol (mogelijk is het zomertijd?), terwijl de meesten doorlopen. Ook hier zien we mensen uit verschillende klassen. Bijvoorbeeld twee modieus geklede dames die onderlangs het beeld uitlopen, ongetwijfeld op weg naar de destijds chicste winkelstraat van Amsterdam: de Kalverstraat. De twee opnames van de Dam geven kortom een prachtige microkosmos op zich, de werkelijkheid achter de picturale verbeelding van George Breitners schilderijen. Ik denk daarbij met name aan zijn aquarel Gezicht op de Dam (ca. I895, Rijksmuseum, Amsterdam).

Als we meer formeel kijken naar de twee opnames, dan wordt ons oog getroffen door de diagonale zichtlijnen in beeld, duidelijk gekozen vanwege het voordeel van 
een grotere sensatie van driedimensionaliteit in beeld. In de film met het Paleis hebben we een soort Andreaskruis van gebouwen, wegen en passerend verkeer. Dit schept een formele consistentie. Aan de andere kant zorgen de voetgangers die van alle kanten oversteken voor een tegenspreken van deze consistentie. In de film met de Beurs vormen de tramsporen een wijde boog die de trams dwingen een strikte koers te volgen. Opnieuw zien we een diagonaal kruis in de structuur van de gebouwen, maar ook hier spreken de van alle kanten overstekende voetgangers deze solide structuur tegen. Zij bieden zo hun persoonlijke verhaal aan, meer dan wanneer ze allemaal strikte richtingen hadden moeten volgen. Anderzijds is het op deze manier moeilijk te bepalen waar of op wie je de aandacht moet richten; een beetje als in widescreen cinema wanneer er te veel informatie tegelijkertijd gegeven wordt. Een democratische kijk, zou je kunnen zeggen, maar ook wat verwarrend. Erg Nederlands op die manier. Deze registratie van de Dam en zijn publiek staat in contrast met opnames van Biograph die toch enigszins geregisseerd lijken, zoals PRIN. SENGRACHT (1899) waar 'toevallig' heel wat gevarieerd volk over de brug loopt waar de boot onderdoor vaart. Of WEESHUIS-QUAESTIE (I899), een van de inserts van DE NIEUWE PRIKKEL, waarbij Amsterdamse weesmeisjes achter het Paleis zijn gefilmd die keurig in het gelid lopen.

Door het vaststellen van de breedte van de camerahoek en de informatie in beeld kunnen we de plek bepalen waar de camera de twee opnames heeft gemaakt. Wat betreft de opname van de Beurs moet de camera op de eerste of tweede verdieping van het gebouw Zeemanshoop of van de herensociëteit De Groote Club hebben gestaan, beide de ingang van de Kalverstraat flankerend. De Groote Club had op de eerste verdieping een uitstekend balkon waarvandaan de opname met niet al te veel moeite gemaakt kan zijn. ${ }^{20} \mathrm{Bij}$ de andere opname heeft de camera ook op een verhoging gestaan, vermoedelijk bovenaan het bordes van de trappen van de Beurs, met zicht op het Paleis. Hierbij is onduidelijk of de opname met een standaardlens is geschoten of met een telelens, maar volgens Barry Salts Film Style and Technology (1983) en volgens Deac Rossell, expert in de technologie van de vroege film, bestonden telelenzen al in deze vroegste jaren en werden ze juist voor actualiteitenfilms gebruikt. $^{2 \mathrm{I}}$

Bij de twee opnames van de Dam zien we een iconografische, intermediale connectie, die deels afwijkt van eerdere verbeelding van de Dam en deels ermee overeenkomt. Waar fotografie van de Dam al zeer populair was in de negentiende eeuw, vallen de eerste filmbeelden daarvan nagenoeg samen met de vroegste geillustreerde ansichtkaarten met foto's van de Dam, in zwart-wit of ingekleurd. Een grote hoeveelheid negentiende-eeuwse foto's maar ook veel ansichtkaarten van rond I900 tonen het Koninklijk Paleis en het monument van grondhoogte af en in hun volle afmetingen. De filmopname daarentegen is van een hoger niveau genomen en laat alleen een deel van het Paleis en het monument zien. ${ }^{22}$ Blijkbaar was het voor de maker niet nodig om de volle afmetingen van Paleis en monument te tonen. Wat dat betreft zit deze opname tussen de Biograph-film van de Dam en de andere opname met de Beurs in. Terwijl andere beelden, zoals de ansichtkaarten, het Paleis 
vaak in het centrum van het beeld plaatsen, laat de filmopname de rechterzijdes van de pilasters in de gevel zien, zodat de opname enigszins van rechts is gemaakt, wat het beeld minder plat maakt en wat de positie van de camera bij de Beurs bevestigt. De andere opname van de Noordzijde van de Dam is ook curieus vanwege zijn positie. In de collectie van het Amsterdams Stadsarchief zien we verschillende laat negentiende-eeuwse foto's die al eerder vanuit hetzelfde standpunt (camerahoek, camerahoogte) zijn gemaakt als de filmopname met de Beurs. Misschien bood De Groote Club regelmatig betaalde faciliteiten voor dergelijke opnames? Het archief van de sociëteit biedt helaas geen uitsluitsel hierover. Toch is het wel opvallend dat de meeste ansichtkaarten van rond I900 die de Noordzijde van de Dam afbeelden meestal vanuit een lager perspectief zijn genomen en bovendien dichter naar het Rokin toe, zodat we een lang perspectief over het Damrak krijgen geboden, in de richting van het Centraal Station, dat als skyline fungeert. Een hoogwaardige scan uit het celluloid van de opname met de oude Beurs laat op de achtergrond de staketsels van de nieuwe Beurs in aanbouw goed zien. Op basis daarvan en in combinatie met beeldmateriaal en data omtrent de Beurs van Berlage valt deze filmopname, ook rekening houdend met zonnestand, schaduwlengte, temperatuur en beeldhoek, nu te determineren als opgenomen in augustus $1900 .{ }^{23}$

\section{Context: de actualiteitenfilms van Anton Nöggerath sr., Urban en Warwick}

Terugkomend op Burkes argument dat we de functie van deze visuele bronnen moeten incorporeren in ons onderzoek: waar zijn deze beelden vertoond? Ik zou willen antwoorden met de titel van Carlo Ginzburgs studie: Omweg als methode, ${ }^{24}$ maar nog meer is te denken aan Giuliana Bruno's Streetwalking on a ruined map. ${ }^{25}$ Daarin neemt zij een klein restant Napolitaanse zwijgende films als vertrekpunt en juist het gebrek aan filmmateriaal buigt ze om. Dit doet zij door in grotere culturele kring eromheen te bewegen en zo film te 'mengen' met fotografie, architectuur, literatuur en medische wetenschap. Bij de opnames van de Dam hebben we geen hard bewijs wie deze heeft gemaakt en waar ze zijn vertoond. Tegelijkertijd, en dat is de praktijk en het dilemma van menig filmarchiefmedewerker, treft het materiaal ons met zijn aanwezigheid: het is er, ook al staat het niet in de naslagwerken. Probeer nu zelf maar te interpreteren.

In ons geval kunnen we alleen een vermoeden uitspreken vanwege het corpus waarin de opnames zich bevinden, omdat we kunnen vaststellen dat een flink deel ervan opnames zijn van Franz Anton Nöggerath senior (I859-1908). Vanaf i896 vertoonde hij films in zijn variététheater Flora aan de Amstelstraat in Amsterdam. ${ }^{26}$ Als de Dam-films van Nöggerath zijn, dan zijn ze hoogstwaarschijnlijk vertoond in Flora. Flora vertoonde regelmatig gefilmde actualiteiten als slotnummer van de variétévoorstellingen. Meerdere opnames werden achtereenvolgens vertoond. Dat betekent dat de films op elkaar kunnen hebben gereageerd, maar ook kan er interactie met de voorafgaande live acts zijn geweest. Live commentaar tijdens de projectie 
of vooraf kan ook de betekenis van de beelden gestuurd hebben, net zoals dat was gebeurd bij de filmische inserts in de revue DE NIEUWE PRIKKEL. We weten het echter niet, want de Amsterdamse dagbladen Algemeen Handelsblad en Nieuws van de Dag vermelden geen vertoningen van de Dam-opnames in Flora. ${ }^{27}$ Dat laatste was niet helemaal vreemd, omdat, zoals Luuk Bruins opmerkt in zijn scriptie over de voorstellingen in Flora, advertenties soms erg algemeen waren en geen individuele titels noemden. Oorspronkelijke programma's zijn maar sporadisch overgebleven, zodat die geen soelaas bieden. ${ }^{28}$ Ook in de filmografie van Bruins van Nöggeraths filmproductie komen de opnames niet voor. ${ }^{29}$

Wel werd in het Algemeen Handelsblad van 30 september I899 (tweede blad) geadverteerd voor een aantal films die werden vertoond in Theater Carré, de concurrent van Flora. ${ }^{30}$ Eén daarvan was UITGAAN VAN DE GROOTE KOOPMANS-BEURS OP I2 SEPT. LL. Enkele dagen na de advertentie van 30 september berichtte het Algemeen Handelsblad over het programma waarbinnen de film over de Dam werd vertoond: '(...) volgt The American Biograph, die wij zeker niet onvermeld mogen laten, al is deze bij Carré ook geen nieuwigheid meer. (...) Dan komt weer EEN RATELENDE SPOORTREIN en een alleraardigst KIJKJE BIJ HET UITGAAN VAN DE BEURS. Menig beursbezoeker zal zich daar zeker terugvinden.(... '. ${ }^{3 \mathrm{I}}$ Het concurrerende dagblad Nieuws van de Dag merkte de film bij Carré ook op: '(...) bij de vertooning van de levende beelden boekt een nieuw beeld, HET UITGAAN VAN DE BEURS, zeer de aandacht'. ${ }^{32}$ De vermelding van 'Biograph' zou erop kunnen duiden dat UITGAAN VAN DE GROOTE KOOPMANS-BEURS een andere film is dan de twee opnames van de NCF-collectie, want Nöggeraths films werden juist als 'The Royal Bioscope' aangeduid, verwijzend naar Urbans Bioscope projector. Een bevestiging van dit verschil zien we ook in de lengte van de Dam-opnames, beide van meer dan een minuut, terwijl de Biograph-opnames dat in het algemeen bij lange na niet haalden.

Vermoedelijk was de distributieradius van de lokale opnames van de Dam beperkt, in tegenstelling tot de actualiteitenfilms die media events betroffen als de kroning van Wilhelmina in 1898 of haar huwelijk met Hendrik von MecklenburgSchwerin in I90I, waarvan we weten dat ze in Engeland en Duitsland gedistribueerd zijn. Binnen het corpus van het NCF bevindt zich een opname van de huwelijksstoet tijdens het huwelijksfeest van het koninklijk paar in Den Haag. Beide events werden niet alleen door de American Biograph gefilmd maar ook door Nöggerath, die zijn opnames internationaal liet distribueren door de Britse distributiemaatschappij The Warwick Trading Company, geleid door de Amerikaan Charles Urban. 33 Al sinds december 1897 had Nöggerath een contract met ze waardoor hij hun vertegenwoordiger voor Nederland, Noorwegen en Denemarken werd. Vermoedelijk ontstond het contact via Oskar Messter, die in september I897 filmvoorstellingen in Flora had gegeven en hem een projector had verkocht. Messter was namelijk voor Warwick al vertegenwoordiger voor Duitsland en Oostenrijk-Hongarije. In I898 kocht Nöggerath bij Urban een nieuwe projector, die American Bioscope heette. Die kon ononderbroken vijftien tot twintig minuten projecteren, waar de 


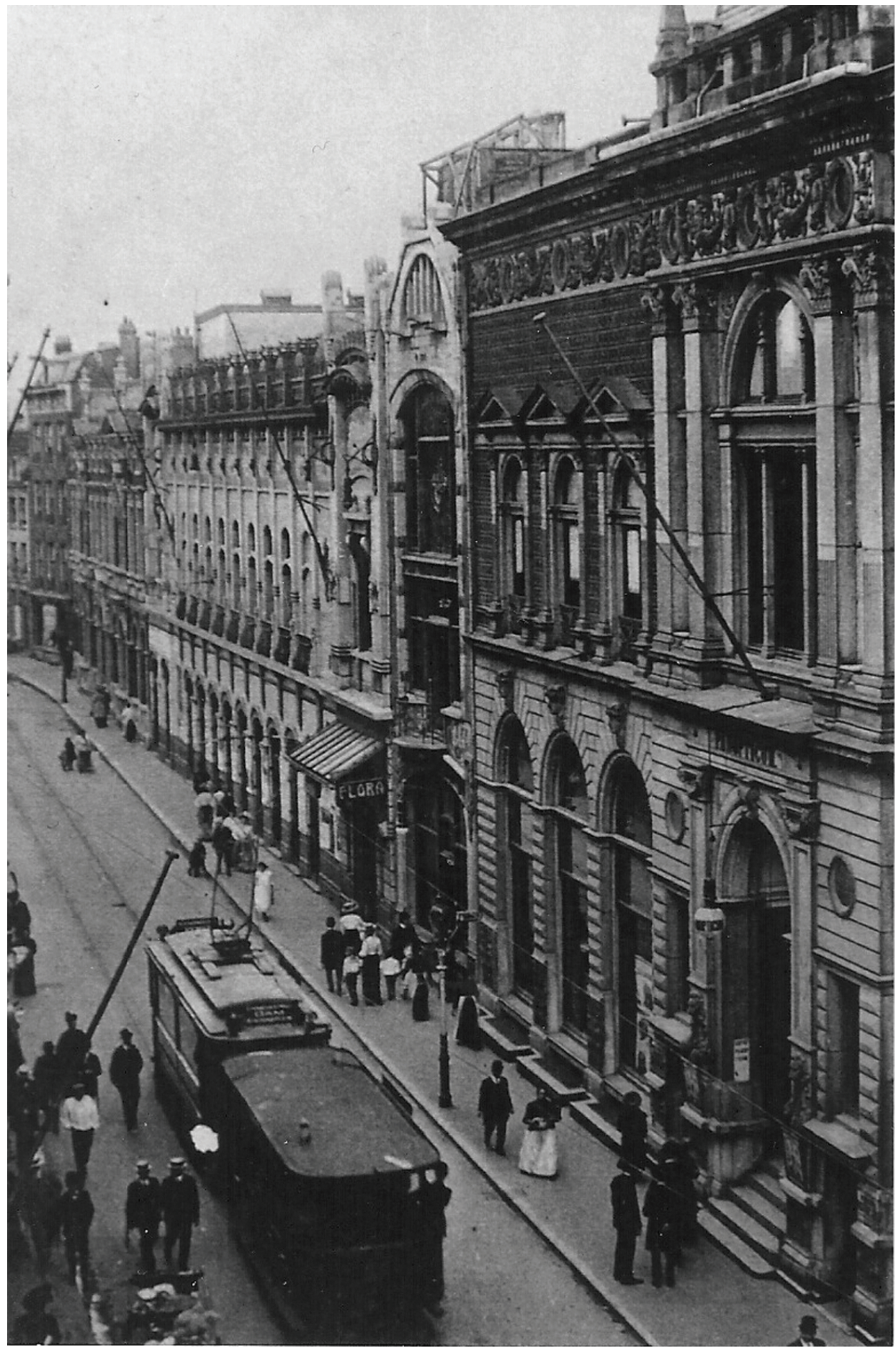

Amstelstraat met Flora-theater in Amsterdam, rond de eeuwwisseling. Bron: collectie EYE Filminstituut Nederland 
Messter-projector maar maximaal 45 seconden kon projecteren. De projectoren van Urban hadden daarnaast zowel een afwikkel- als een opwikkelspoel - wat nog niet gebruikelijk was - en werden met de hand aangedreven, zodat logge batterijen zoals bij Biograph niet nodig waren. Urban was niet alleen filmproducent maar ook vertegenwoordiger van de films van Méliès, Lumière en de Brighton School-filmers George Albert Smith en James Williamson. Urban was dus duidelijk een belangrijke speler voor Nöggerath. Die had dat goed door, want hij stuurde meteen in december 1897 zijn oudste zoon naar Warwick om in Urbans laboratorium en later daar ook als cameraman te leren werken.34 Niet alleen Urbans films kwamen naar Nederland, ook hijzelf kwam in I898 over om namens Nöggerath de kroning van Wilhelmina te filmen. Al in I973 merkte Adriaan Briels op: 'Minstens twee ondernemers, Nöggerath en de Nederlandsche Biographe en Mutoscope Maatschappij, Utrechtsestraat ig te Amsterdam, hebben "gekinematografeerd" wat op de Dam te zien was en er goede zaken mee gedaan. Misschien heeft ook M.H. Laddé er gestaan.'35 Laddé, een Amsterdams fotograaf, die al in I896 ZWEMPLAATS VOOR JONGELINGEN TE AMSTERDAM en het kluchtje DE GESTOORDE HENGELAAR had gefilmd en dus misschien ook de opnames van de Dam kan hebben gefilmd! - heeft dan wel zijn best moeten doen. William Dickson leek namelijk een monopolie op de opnames van de kroning te hebben. ${ }^{36}$ Maar niet iedereen trok zich daar wat van aan.

In de door Luke McKernan gepubliceerde memoires van Charles Urban, A Yank in Britain. The Lost Memoirs of Charles Urban, film pioneer, 37 lezen we dat Urban voor Nöggerath de opnames van de kroning zelf verzorgde:

'One of the first important historical events which I photographed outside of England, was the coronation of Queen Wilhelmina at Amsterdam, Holland. A. Nöggerath, owner of the Concert Flora in Amsterdam to whom I had sold a Bioscope outfit and all new film issues - was most anxious that this coronation should be filmed by us, so that he may exhibit the same at the Concert Flora. A rival theatre [Carré] which was showing regularly the American Biograph, had arranged with the town council and police that only one stand should be erected in the small square, facing the Neue Kirk [sic] where the ceremony was to take place. The exclusive rights to use this stand for the cameras had been secured for the American Biograph. This meant, excluding everyone else from securing this event, which threat spurred me on to try to get the pictures irrespective of these "exclusive" rights. 38

Urban kwam dit gelukkig een paar dagen voor de kroning al te weten. Hij stak het Kanaal over en met Nöggerath ging hij een aantal huiseigenaren af die vanuit hun ramen zicht op de Nieuwe Kerk hadden. Urban betaalde een fikse som om een gunstig raam te krijgen dat qua ligging en lichtval perfect was, vlakbij de plek die Biograph had bemachtigd maar dan zeven voet hoger en onopvallend. Binnen 48 uur was Urban op en neer naar Engeland om een camera en onbelichte film op te halen. De ochtend daarna brachten Nöggerath en hij de camera en de films naar hun uit- 
kijkpost, waar ze zagen hoe Koopman en Dickson met veel moeite hun logge camera met enorme reservebatterijen aan het opstellen waren. Zelf hadden ze het een stuk gemakkelijker:

'Our camera was operated by hand and was portable, a great advantage over the Biograph, which used ten times the extent of film we required as their pictures were four times larger than the Edison size [eigenlijk maar twee keer, want bijna $2 \times 35 \mathrm{~mm}$ ] and while we only used sixteen pictures on each foot of film per second, the Biograph pictures were exposed at the rate of forty pictures per second run through the camera. (...) I rather liked Dickson's arrogance and we had many a battle of wits in securing picture rights and rushing the time of exhibiting the results, each at his respective theatre. 39

Waar Dickson zijn films in Londen in het Palace Theatre vertoonde, deed Urban dat bij het Alhambra Theatre. Ongetwijfeld hebben daar dus ook Urbans opnames van de kroning van Wilhelmina gedraaid. In Amsterdam draaiden de films niet alleen bij Nöggeraths Flora-theater maar ook in Circus Renz. Voor Nederland betekenden de kroningsfilms van Urban (Warwick) en Nöggerath en die van Dickson (Biograph) een doorbraak, aldus Bruins: 'Beelden van de inhuldiging vormden immers een wel zeer legitieme reden om een filmvoorstelling te bezoeken. Daarnaast zorgde de actualiteit van de opnames er voor dat het publiek voor de films kwam en niet alleen voor het feit dat de beelden bewogen.'40 Maar omdat er geregeld meerdere filmers bij grote media events actief waren, is op basis van enkel geschreven bronnen soms lastig vast te stellen over wiens film of opname we het nu hebben.

De citaten van Urban kunnen gezien het feit dat dit memoires zijn, met een korrel zout genomen worden. Wel bevestigen ze dus dat Nöggerath de projector van Urban gebruikte, ${ }^{4 \mathrm{I}}$ maar mogelijk kocht hij ook de kleine, beweeglijke camera van Urban om daar nadien zijn eigen lokale actualiteitenfilms mee op te nemen..$^{2}$ Dit vermoeden wordt bevestigd in een advertentie van Nöggerath voor zijn zogenaamde Riesen-Graphophone 'Flora' (1899).43

Daarin zien we vermoedelijk Nöggerath zelf aan tafel zitten, met links van hem het bordje Bioscope en rechts een man met baard die een camera bedient die op een statief staat. De camera is van bescheiden formaat en wordt handmatig met een zwengel bediend; het magazijn staat bovenop. ${ }^{44}$ Dit moet haast wel Nöggeraths camera zijn geweest waarmee hij zijn eigen actualiteiten heeft gefilmd, of liever gezegd laten filmen, omdat Donaldson, Van Gelder en Bishoff aangeven dat hij nooit zelf heeft gefilmd. Hij zou dit hebben overgelaten aan assistenten als Leon Boedels en Johann Theodor Vierboom. ${ }^{45}$ Dit verklaart ook waarom Nöggeraths opnames gemakkelijk meer dan een minuut lang konden zijn. Noemde Nöggerath zijn voorstellingen aanvankelijk American Bioscope, na de films van de kroning herdoopte hij die in The Royal Bioscope. Het werd zijn eigen merknaam waarmee hij ook elders filmprogramma's liet vertonen, tot in Duitsland toe. De concurrentie tussen Biograph en Urban herhaalde zich overigens in I9or bij de opnames van het 


\section{Riesen-Graphophone „Flora"}

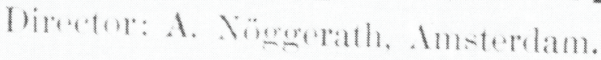
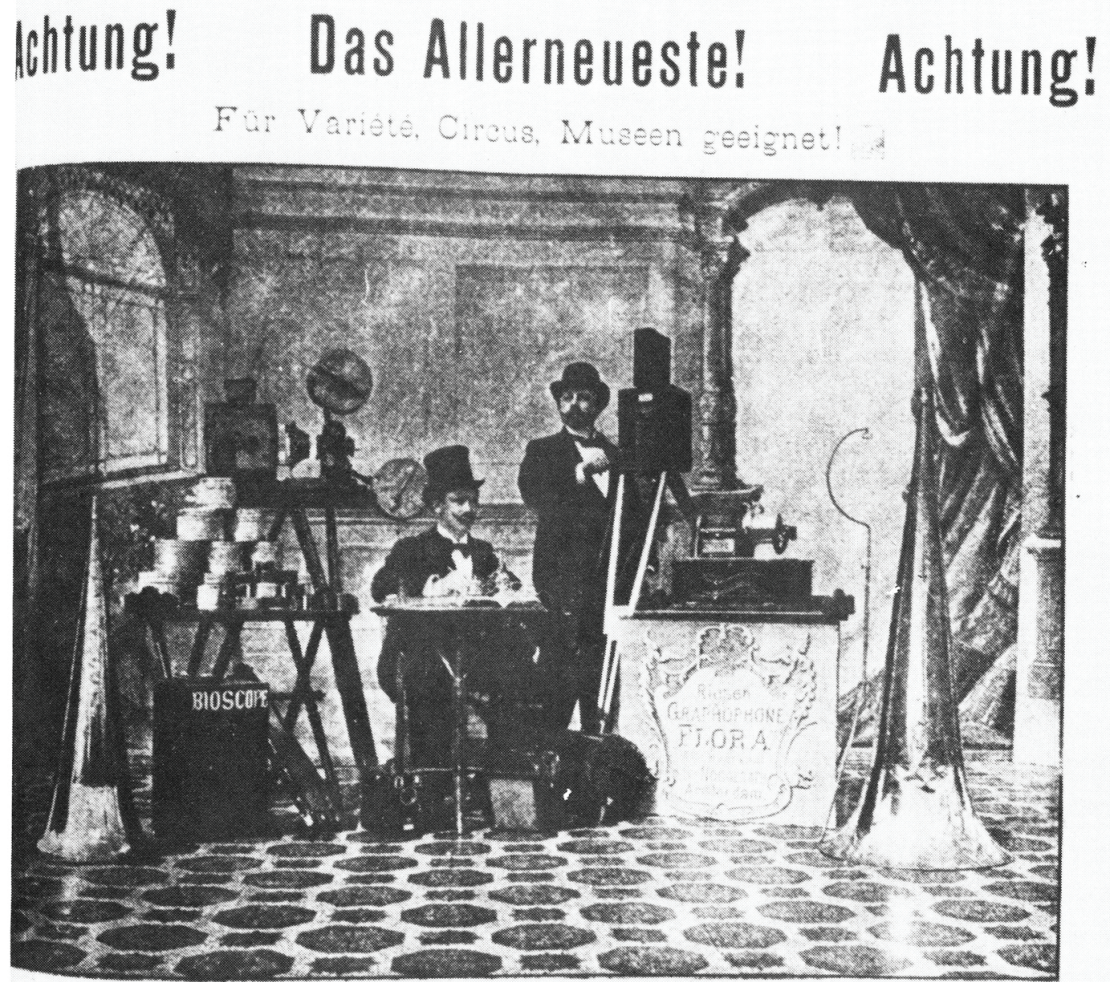

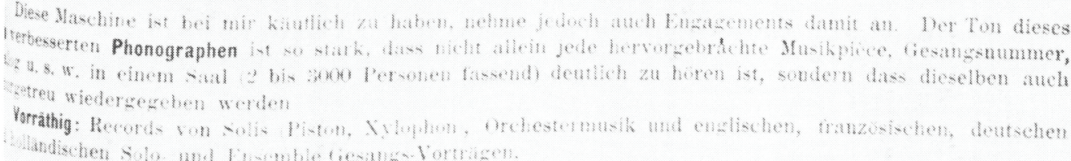

Riesen-Graphophone Flora, 1899. Bron: collectie EYE Filminstituut Nederland

huwelijk van Wilhelmina en Hendrik. Waar Urbans opnames van de kroning vermoedelijk verloren zijn gegaan, zijn de opnames van Nöggerath en die van Biograph van de huwelijksstoet in Den Haag bewaard gebleven. Opmerkelijk daarbij is dat de Biograph-opname veel korter is en niet de Gouden Koets met het koninklijk paar laat zien. Wel zijn beide opnames vanuit precies eenzelfde standpunt genomen, dat wil zeggen rechts van de aankomende stoet, met de camera diagonaalsgewijs naar achteren gericht. Beide laten ook een deel van de erebogen zien waar de koetsen en ruiters onderdoor reden. $4^{6}$ 
De bovengenoemde opname van Nöggerath zal nader worden besproken in deel 2 van dit artikel. Daarin gaan we in op de overige vroege non-fictiefilms van het Nederlandsch Centraal Filmarchief: films met betrekking tot het Koninklijk Huis, Paul Kruger en zijn generaals, de Rotterdamse Maasbruggen en de Utrechtse Maskeradeoptocht van I90I. Ook bekijken we dan het tweede leven van het materiaal bij het NCF en de achtergrond van de schenker.47

Wordt vervolgd in TMG 14/2011-1.

\section{Noten}

I Het Lichtbeeld, jrg. 6, nr. II, november 1928, p. I96-I97. Nationaal Archief, Den Haag (NA), archief Nederlandsch Centraal Filmarchief (NCF).

2 Amsterdamsche Courant, 29 augustus 1902, eerste blad; Nieuws van de Dag, I september I902, vijfde blad, p. I5. Franz Anton Nöggerath junior memoreerde zelf in de brochure Ons Bioscopisch bedrijf voorheen en thans (s.a., reprint Stichting Film Manifestatie, Amsterdam 1975), p. 6-7: 'Flora brandde af en mede verbrandden de met hare historische waarde aanwezige films, de toestellen en aparaten [sic], ter waarde van $\mathrm{f} 50.000,-$. Dit was echter slechts voor 5000,- verzekerd.'

3 Voor de geschiedenis van het Nederlandsch Centraal Filmarchief, zie Bert Hogenkamp, 'Het Nederlandsch Centraal Filmarchief', in: Skrien 137, september-oktober 1984, p. 6o-63, en idem, De Nederlandse documentaire film 1920-1940, Van Gennep/Stichting Film en Wetenschap, Amsterdam/Utrecht I988, p. I4-I5.

4 Bij het Filmmuseum is dat gebeurd via compilaties als Journaal 1900. Bekende figuren 1900-1920 en Amsterdam 1900. Ook de NCF-compilatietitel komt voor. Bij Beeld en Geluid bestaat de compilatie Gebeurtenissen rond 1900.

5 Peter Burke, Eyewitnessing. The Use of Images as Historical Evidence, Cornell University Press, Ithaca New York 200I, met name zijn 'Introduction: The Testimony of Images', p. 9-2I.

6 Burke, Eyewitnessing, p. I3.

7 Walter Benjamin, Het kunstwerk in het tijdperk van zijn technische reproduceerbaarheid, Boom, Amsterdam 2008.

8 E.H. Carr, What is History?, Palgrave MacMillan 2002 [Penguin I96I]; geciteerd in Burke, Eyewitnessing, p. 2I.

9 Catalogus Filmmuseum.

Io Dat wordt aangegeven in Michelle Aubert \& Jean-Claude Seguin (eds.), La Production cinématographique des Frères Lumière, BIFI/Editions Mémoires du cinéma, Paris I996.

II Biograph begon op 20 augustus I898 met filmvertoningen in het toen net opgeknapte Theater Carré, kort voor de kroning van Wilhelmina dus. In Rotterdam werden Biograph-voorstellingen gehouden in het Circus-Variété. Voor de activiteiten van Biograph in Nederland, zie Mark van den Tempel, “'Als Daguerre dat eens kon aanschouwen". The Mutoscope \& Biograph Company als voorloper van het bioscoopjournaal', Jaarboek Mediageschiedenis 8, I997, p. 5I-72. Voor het bijzondere restauratieproject van het Biograph-materiaal, zie Mark van den Tempel, 'Making them Move Again: Preserving Mutoscope and Biograph', Griffithiana 66/70, 1999/2000, p. 225-240.

I2 Dickson voegde zich daarbij in een traditie, want niet alleen hadden de gebroeders Lumière hun films in 1896 eveneens in Scheveningen laten vertonen, maar ook werd in 1896 in Amsterdam een van de oudste bekende opnames van Nederland vertoond: DE ZEE BIJ SCHEVENINGEN. Evenals een andere typisch Nederlandse titel, AAN BOORD VAN DE MAILBOOT 'KONINGIN WILHELMINA', maakte de titel onderdeel uit van een programma van de zg. Théatrographe, een naam die wijst op de projectieapparatuur van de Britse filmpionier Robert W. Paul. In Rommy Albers et al. (eds.), Film in Nederland, Ludion, Amsterdam/ Gent 2004, p. 29I wordt door Albers echter beweerd dat deze film - aangeduid als DE ZEE TE SCHEVENIN- 
GEN - vermoedelijk een film is van de gebroeders Lumière die binnen hun programma op I2 juni I896 in het Scheveningse Kurhaus werd vertoond. De titel komt echter in het boek van Aubert en Seguin niet voor.

I3 De revue ging op 27 september 1899 in première. Mark van den Tempel, "'En zie ik duizendmaal vergroot..." De Nederlandsche Biograaf- en Mutoscope Maatschappij en de films uit De Nieuwe Prikkel Revue', Jaarboek Mediageschiedenis 5, I993, p. 2I-38. De revue werd niet in Carré gegeven, maar in het Grand Théâtre van de gebroeders van Lier in de Amstelstraat. Die hadden in februari I899 de filmvertoningen van Biograph van Carré overgenomen. Bij de opnames van de Nederlandsche Biograaf- en Mutoscope Maatschappij van I899 wordt aangegeven dat alle opnames mogelijk door Emile Lauste zijn gedaan. Zie hiervoor: Barry Anthony, 'The Biograph Collections in Amsterdam and London', Griffithiana 66/70, 1999/2000, p. 259-275.

I4 E.W. Moes (red.), Amsterdamsch Jaarboekje voor 1901, L.J. Veen, Amsterdam I9oI. De jaarboekjes bevatten steeds overzichten vanaf najaar twee jaar eerder tot en met september van het vorige jaar, in dit geval dus oktober 1899 tot en met september 1900 .

I5 Eva Hielscher, Stadtbild(er): Amsterdam im frühen Film \& auf Ansichtskarten um 1900, Bauhaus-Universität, Weimar 2005, p. 87-88, 94-97.

I6 Marc Augé, Non-Places: Introduction to a Anthropology of Supermodernity, Verso, New York 1995.

I7 Nederland won de Tiendaagse Veldtocht, maar werd door de Fransen gedwongen alsnog België af te staan.

I8 De opening door koningin Wilhelmina vond plaats op 27 mei I903.

I9 Op I januari I900 nam de gemeente Amsterdam de Amsterdamse Omnibus Maatschappij over, die de Amsterdamse paardentrams vanaf hun introductie in I875 had geëxploiteerd. Er waren in I900 zestien paardentramlijnen actief. Al snel na de overname begon de gemeente de paardentrams door elektrische tramlijnen te vervangen, al zou de laatste paardentram pas in I9I6 verdwijnen. Op 8 augustus I903 reed de eerste elektrische tram over de Dam, lijn 3, met toen nog eindhalte Dam. Al in I904 werden de eindhaltes van lijn I, 2 en 3 naar het Centraal Station verlegd. Lijnen 2 en 3 deden al snel de Dam niet meer aan, in I9II lijn I ook niet meer. De Dam was niet langer een verkeersknooppunt.

20 De archieven van Zeemanshoop en De Groote Club in het Amsterdamse Stadsarchief leverden geen informatie over de opname op.

2I Barry Salt, Film Style and Technology: History and Analysis, Starword, London 1992/[I983], p. 33. Deac Rossell aan de auteur, I november 2009. Rossell merkte op dat men in de vroegste jaren zowel lenzen van fotocamera's gebruikte als zelf ontworpen filmlenzen. De Britse filmpionier John Alfred Prestwich kon bijvoorbeeld al in I898-I899 75 mm lenzen aan zijn camera's vastmaken. Het onderzoek naar lenzen in de vroegste jaren van de film staat echter nog in de kinderschoenen, aldus Rossell.

22 De foto's zijn onder meer te bezichtigen in de digitale beeldbank van het Stadsarchief: www.beeldbank.amsterdam.nl. De ansichtkaarten zijn in eigen bezit.

23 Met dank aan Gé Joosten.

24 Carlo Ginzburg, Omweg als methode. Essays over verborgen geschiedenis, kunst en maatschappelijke herinnering, sUn, Nijmegen I988, p. 206-26r. Hierin mengt hij onder meer morfologie met geschiedenis, met name in zijn essay 'Sporen. Wortels van een indicieparadigma'.

25 Giuliana Bruno, Streetwalking on a Ruined Map. Cultural Theory and the City Films of Elvira Notari, Princeton University Press, Princeton NJ 1993.

26 Zie mijn biografie van Nöggerath op http://www.victorian-cinema.net/noggerath.htm.

27 In het door Rommy Albers en Dorette Schootemeijer (Filmmuseum) aangelegde databestand van besprekingen van en advertenties voor film in Amsterdam tot I9I4 komen de Dam-opnames niet voor. De huidige digitalisering van kranten door de Koninklijke Bibliotheek zou mogelijk nieuw materiaal kunnen opleveren.

28 Luuk Bruins, De programmering van film als variéténummer door Franz Anton Nöggerath, Universiteit Utrecht, Utrecht 1998. Zie ook: Nico de Klerk, 'A few remaining hours: News films and the interest in technology in Amsterdam film shows, I896-I9I0', Film History, vol. II, no. I, I999, p. 5-I7.

29 Bruins, De programmering van film als variéténummer, p. II9-I22.

30 Algemeen Handelsblad, 30 september 1899 , tweede blad.

3I Algemeen Handelsblad, 3 oktober 1899 , ochtendblad. 
32 Nieuws van de Dag, 4 oktober i899, derde blad, p. II.

33 De firma heette oorspronkelijk Maguire \& Baucus.

34 Voor de ervaringen van Nöggerath junior bij Warwick en andere Britse firma's, zie mijn artikel 'Chapters from the Life of a Camera-Operator. The Recollections of Anton Nöggerath- filming news and non-fiction, I897-1908', Film History, vol. II, 3, I999, p. 262-28I.

35 Adriaan Briels, Komst en plaats van de Levende Photographie op de kermis, Van Gorcum \& Co, Assen I973, p. 35. Voor de opnames van Dickson/Biograph en Urban/Nöggerath, zie ook www.cinemacontext.nl/id/Fo32089 en www.cinemacontext.nl/id/Fo32126.

36 In 1896 werd overigens ook door de Amsterdamse fotograaf M.H. Laddé de film ZWEMPLAATS VOOR JONGELINGEN TE AMSTERDAM vervaardigd, die samen met zijn andere films SPELENDE KINDEREN (I896?) en GESTOORDE HENGELAAR (I896) in de reisbioscoop van Christiaan Slieker werden vertoond. Ook deze films zijn nooit opgedoken. Ruud Bishoff, 'De zwijgende speelfilm', in: Karel Dibbets \& Frank van der Maden (eds), Geschiedenis van de Nederlandse film en bioscoop tot 1940, Wereldvenster, Houten I988, p. 53-IO4. Bishoff vermeldt dat Laddé een studiootje in Buiksloot had en zijn buitenopnames op de Dam maakte. Zie ook: Briels, Komst en plaats van de Levende Photographie, p. 29-30. Briels vermeldt op p. 33 dat Laddé ook nadien nog lokale opnames maakte, dus behalve Nöggerath zou ook hij de opnames van de Dam kunnen hebben gemaakt.

37 Luke McKernan, A Yank in Britain. The Lost Memoirs of Charles Urban, film pioneer, The Projection Box, Hastings I999.

38 McKernan, A Yank in Britain, p. 62.

39 McKernan, A Yank in Britain, p. 62-63. Zestien frames per seconde was een gebruikelijke opnameen projectiesnelheid voor de Warwick-films destijds, ook al is onbekend of men daar rigide aan vasthield. Belangrijker is dat Urban zich hier profileert ten opzichte van Biograph.

40 Bruins, De programmering van film als variéténummer, p. 42.

4I Dat wordt ook nog eens bevestigd in een foto van Nöggeraths projector die een exemplaar van de Bioscope-projector is, aldus Urban-kenner Luke McKernan. Afgebeeld in: Jacques Klöters, 100 jaar amusement in Nederland, Uniepers/Staatsuitgeverij, Amsterdam/Den Haag I987, p. 65.

42 De meeste filmapparatuur die Urban verkocht kwam van de Brit Alfred Darling. Zie http://www.victorian-cinema.net/urban.htm en Luke McKernan, 'Alfred Darling', in: Richard Abel, Encyclopedia of Early Cinema, Routledge, New York 2005, p. I64-165.

43 Zie Klöters, 100 jaar amusement in Nederland, p. 65. In I899 liet Nöggerath zijn reuzengrammofoons horen en zijn Bioscope-films zien in een gehuurde ruimte aan Rembrandtplein 29. De entree was gratis, mogelijk als douceurtje omdat zijn theater werd verbouwd. Bruins, De programmering van film als variéténummer, p. 9I.

44 Hij lijkt wat op de Prestwich-camera zoals afgebeeld in Blom, 'Chapters from the Life of a CameraOperator', p. 269, afb. 7. Nöggerath junior loofde in zijn memoires de Prestwich-apparatuur, omdat die klein, compact en licht van gewicht was.

45 Bruins, De programmering van film als variéténummer, p. 43, verwijst naar: Henk van Gelder, 'De eerste Nederlandse filmfabriek', Ons Amsterdam Io, I99I, p. 240; Ruud Bishoff, 'Hollywood in Holland', p. I6; Geoffrey Donaldson, 'Wie is wie in de Nederlandse film tot I930: Nöggerath (senior)', Skrien, p. 34-36; en Geoffrey Donaldson, 'Wie is wie in de Nederlandse film tot I930: Vierboom, Johann Theodor', Skrien I26, I983, p. I9. Vierboom filmde bijvoorbeeld DE RAMP VAN HET SS 'BERLIN' TE HOEK VAN HOLLAND (I907). Donaldson noemt daarnaast de namen van Peter Gronen, George Furkel, Martin J. Knoops en ene Bergmann. Ook zijn broer Karl Wilhelm en zijn tweede zoon Theodor zouden voor hem hebben gewerkt als cameraman. Donaldson geeft in een ander artikel aan dat Nöggeraths opnames in Rotterdam waarschijnlijk voor een groot deel zijn gefilmd door Stefan Hofbauer. Geoffrey Donaldson, 'Film in Rotterdam. De eerste jaren', Skrien 98, juli/augustus I980, p. 36-4I.

46 Beide opnames zijn in bezit van het Filmmuseum.

47 Voor de samenstelling van dit artikel ben ik allereerst dank verschuldigd aan wijlen Geoffrey Donaldson, Filmmuseum (Rommy Albers, Dorette Schootemeijer, Rixt Jonkman), Beeld en Geluid (Eva Hielscher, Bert Hogenkamp) en Gé Joosten; verder aan Koninklijk Instituut voor de Tropen, Theaterinstituut Nederland, Stadsarchief Amsterdam, Bernadette Kester, Jacques Klöters, Luke McKernan, Ian Christie, Joseph Garncarz, Karel Dibbets, Hans Bauer, Jeroen Tückermann en Harry Mulisch. 